\title{
All for one...
}

\author{
Many medium-sized university departments feel they are engaged in an unequal struggle against larger \\ and more-entrenched rivals. But there is a way in which they can fight back.
}

$\Lambda$ few years ago, the outlook for physics departments in Scotland was not auspicious. Today, the future is much brighter, thanks to a mechanism that could benefit universities elsewhere. The Scottish Universities Physics Alliance (SUPA), which has forged operational links between six physics departments, looks set to overcome a challenging situation by pooling resources and aiming high.

Like many of their counterparts, the departments in the alliance are fighting for research funds with dozens of rivals, including some élite institutions. They are also competing globally for talented graduate students. Faced with such challenges, medium-sized university departments have few attractive options. They can try to enrol more undergraduates, perhaps by lowering standards, in order to attract block funding that British agencies give to support teaching. In extreme cases, the response has been simply to give up - several chemistry and physics departments have closed in Europe in recent years.

SUPA's founders believe that it is possible to thrive by joining forces. Although this sounds easy, it isn't. Most university department chairs did not work their way up to their positions over decades just to throw whatever influence they have into a pot with five or six of their fiercest local rivals. Universities in every corner of the world experience such rivalries, and variations in quality can make departments reluctant to work with each other on equal terms. And if the universities' top administrators don't buy in, joint ventures between departments are liable to be short-lived.

That may be why the kind of fusion that SUPA has attempted is still relatively rare. But, two-and-a-half years after its formal launch, the experiment is drawing attention from abroad, as well as considerable financial support from both the participating universities and the Scottish Funding Council, which will shortly review a substantial application for funds for the project's second phase.

The alliance is run by a handful of staff in Edinburgh. Physics departments at the participating universities - St Andrews, Edinburgh, Glasgow, Heriot-Watt, Paisley and Strathclyde - have agreed to share authority over hiring decisions and research planning. A board of these departments, together with Ian Halliday, SUPA chief executive and a Scottish physicist of international standing, meets regularly to steer the alliance. The total operation has some 200 faculty members and 400 graduate students, and attracts about $£ 30$ million (US\$60 million) in research grants each year.

At the alliance's annual meeting earlier this month, Halliday said that it is already attracting applications from top-tier candidates for its joint graduate school, and is increasing the calibre of its staff appointments. It remains a challenge to catch the very best students, however, and getting full attendance at video-linked graduate-student classes is also none too easy. Progress in the quality of research - the project's overriding objective - will, of course, take time to achieve.

But if imitation is the highest form of flattery, the project has already enjoyed some measure of success. Similar projects are under way in several disciplines in Scotland and the model has drawn interest from as far

"It is possible to thrive by joining forces - which sounds easy but isn't." afield as Canada and Spain, where departments face the same basic challenges in trying to compete globally. And university administrators and funding agencies seem to be impressed that departments are ready to do something different in order to succeed.

There is also a political aspect to the alliance's momentum. When Roger McClure, chief executive of the Scottish Funding Council, says that SUPA's strong early run has been "forged by centuries of oppression", the alliance's many English-born physicists enjoy the joke. But he has a serious point: it may be easier for universities in a place such as Scotland to find a genuine common cause than in, say, the midlands of England, where a sense of regional identity is less firmly established.

The SUPA example suggests that, where administrators, department heads and faculty members can find a common cause, it is possible for a group of medium-sized departments to make an impact. Those who draw the appropriate lessons should prosper in a scientific world in which departments must be internationally competitive to survive.

\section{Meanings of 'life'}

\section{Synthetic biology provides a welcome antidote to chronic vitalism.}

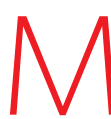
any a technology has at some time or another been deemed an affront to God, but perhaps none invites the accusation as directly as synthetic biology. Only a deity predisposed to cut-and-paste would suffer any serious challenge from genetic engineering as it has been practised in the past. But the efforts to design living organisms from scratch - either with a wholly artificial genome made by DNA synthesis technology or, more ambitiously, by using non-natural, bespoke molecular machinery - really might seem to justify the suggestion, made recently by the ETC Group, an environmental pressure group based in Ottawa, Canada, that "for the first time, God has competition".

That accusation was levelled at scientists from the J. Craig Venter Institute in Rockville, Maryland, based on the suspicion that they had synthesized an organism with an artificial genome in the laboratory. The suspicion was unfounded, but this feat will surely be achieved in the next few years, judging from the advances reported earlier this 